\title{
Title:
}

\section{Leflunomide as a cause of collagenous colitis: an entity to consider}

\section{Authors:}

Paulina Nuñez, Rodrigo Quera, Lilian Flores, Luis Contreras

DOI: $10.17235 /$ reed.2021.8015/2021

Link: PubMed (Epub ahead of print)

Please cite this article as:

Nuñez Paulina, Quera Rodrigo, Flores Lilian, Contreras Luis . Leflunomide as a cause of collagenous colitis: an entity to consider . Rev Esp Enferm Dig 2021. doi: 10.17235/reed.2021.8015/2021.

This is a PDF file of an unedited manuscript that has been accepted for publication. As a service to our customers we are providing this early version of the manuscript. The manuscript will undergo copyediting, typesetting, and review of the resulting proof before it is published in its final form. Please note that during the production process errors may be discovered which could affect the content, and all legal disclaimers that apply to the journal pertain. 


\section{8015}

\section{Leflunomide as a cause of collagenous colitis: an entity to consider}

Paulina Núñez ${ }^{1}$, Rodrigo Quera ${ }^{1}$, Lilian Flores ${ }^{1}$, Luis Contreras ${ }^{2}$

${ }^{1}$ Inflammatory Disease Program. Gastroenterology Department. Universidad de Chile. Santiago, Chile. ${ }^{2}$ Pathology Department. Clínica Universidad de los Andes. Santiago, Chile

Correspondence: Rodrigo Quera

e-mail: rquera@clinicauandes.cl

Keywords: Leflunomide. Collagenous colitis. Chronic diarrhea.

Conflicts of interest: the authors declare no conflicts of interest.

Dear Editor, Leflunomide belongs in the group of disease-modifying anti-rheumatic drugs (DMARDs) used in the treatment of psoriatic, rheumatoid, and reactive arthritis. Approximately $20 \%$ of patients will experience some adverse event, mainly weight loss, abdominal pain, and diarrhea. We describe the clinical, endoscopic, and histological findings in a patient with psoriatic arthritis (PA) who developed severe chronic diarrhea after drug use.

A 64-year-old female began treatment with leflunomide for PA. Good tolerance was reported for the first 18 months, which later evolved to intermittent episodes of liquid stools up to 15 times a day, abdominal pain, significant weight loss, and hypokalemia. The enteric pathogen evaluation, including Clostridioides difficile, was negative. A colonoscopy with ileoscopy showed edema in the colonic mucosa. Biopsies of the colonic mucosa 
demonstrated an increase in intraepithelial lymphocytes and a thickened collagen layer (Fig. 1A-B). Immunostaining for cytomegalovirus was negative. Diarrhea and hypokalemia persisted despite the use of oral budesonide and mesalazine; symptoms improved 20 days after stopping leflunomide.

The fact that symptoms only improved after withdrawing leflunomide establishes a causal relationship between this drug and the probable etiopathogenesis of collagenous colitis. Considering this experience and that of other authors, leflunomide-induced colitis should be included in the differential diagnosis of chronic diarrhea in patients treated with this drug.

\section{REFERENCES}

1. Verschueren P, Vandooren AK, Westhovens R. Debilitating diarrhea and weight loss due to colitis in two RA patients treated with leflunomide. Clin Rheumatol 2005;24:87-90. DOI: 10.1007/s10067-004-1033-1

2. Gugenberger C, Donner P, Maami A, et al. Pesistent diarrhea and loss of weight during therapy with leflunomide. Dtsch Med Wochenschr 2008;133:1730-2. DOI: $10.1055 / \mathrm{s}-0028-1082795$

3. Kwok AMF, Morosin T. Leflunomide-induced colitis in association with enterocutaneous fistula in an immunosuppressed patient with renal and rheumatoid arthritis. J Gastroenterol 2019;12:310-5. DOI: $10.1007 / \mathrm{s} 12328-019-00954-2$ 


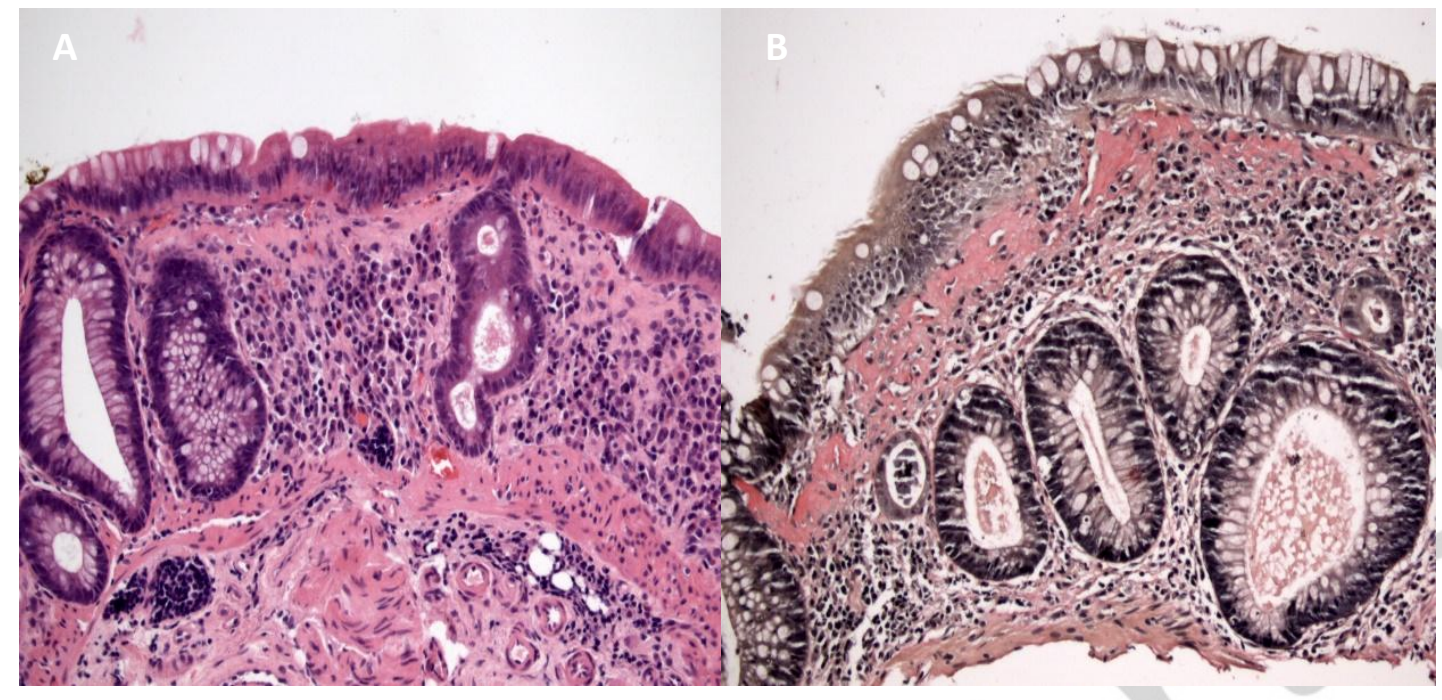

Fig. 1. A and B: colonic mucosa biopsies showing slight architectural distortion and a luminal subepithelial collagen band, which contains fragments of karyorectic cells and erythrocytes (HE x200 and Van Gieson Trichrome x200, respectively). 